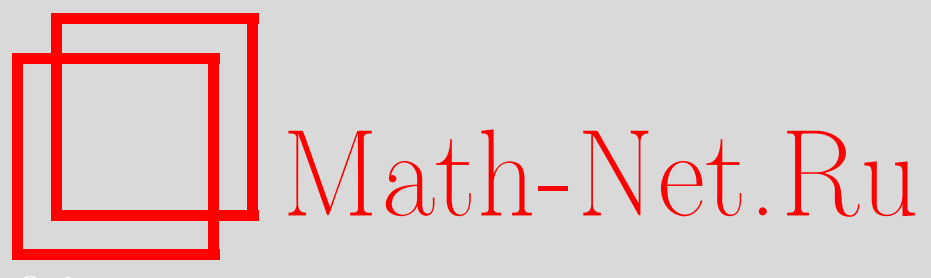

И. А. Ибрагимов, А. М. Ильин, А. П. Киселев, С. В. Кисляков, Л. Д. Фаддеев, Василий Михайлович Бабич (к восьмидесятилетию со дня рождения), УМН, 2011, том 66, выпуск 1, 205-207

DOI: https://doi.org/10.4213/rm9411

Использование Общероссийского математического портала Math-Net.Ru подразумевает, что вы прочитали и согласны с пользовательским соглашением http://www.mathnet.ru/rus/agreement

Параметры загрузки:

IP : 54.210 .77 .194

26 апреля 2023 г., 18:02:43

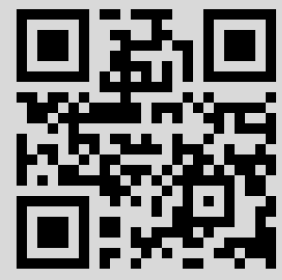




\section{Василий Михайлович Бабич \\ (к восьмидесятилетию со дня рождения)}

13 июня 2010 г. исполнилось 80 лет Василию Михайловичу Бабичу, крупнейшему специалисту по математической теории дифракции и распространения волн, главе петербургской дифракционной школы. Всемирно известны его исследования по теории распространения упругих волн, по локализованным волнам в линейных средах и по асимптотическим методам в теории дифференциальных уравнений. Он является одним из создателей лучевого метода в теории упругих волн. Следует особенно отметить его первые работы в этом направлении ([115]-[117] и др.), отмеченные впоследствии Государственной премией СССР 1982 г. Важным разделом лучевого метода является теория упругих поверхностных волн вблизи искривленных границ, в рамках которой еще в 1962 г. [118] обнаружен эффект, названный впоследствии фазой Берри. К этому направле-

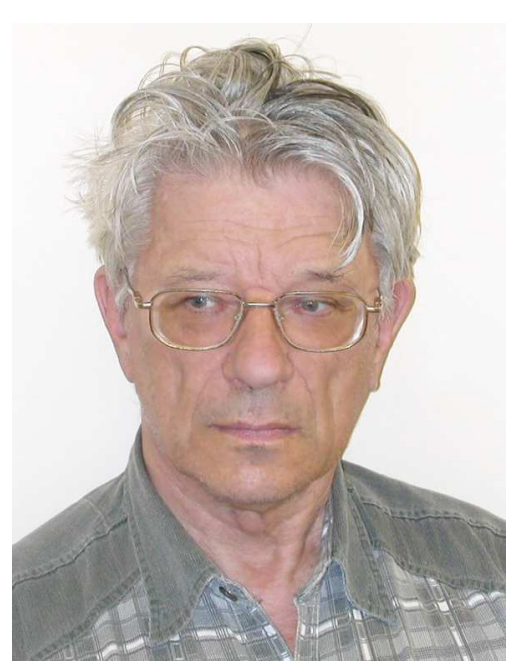
нию примыкает и активно развивающийся в сейсмике метод суммирования гауссовых пучков для описания волновых полей при наличии каустик [15].

Другой областью интересов Василия Михайловича является построение локализованных решений линейных уравнений математической физики. Особенно известна построенная им теория квазимод, локализованных вблизи устойчивых замкнутых геодезических римановых многообразий. Им впервые установлена связь между асимптотикой спектра оператора Лапласа в области с геометрией лучей.

В последние годы Василий Михайлович продолжает активно работать. Он, в частности, занимается задачами дифракции в угловых областях - задачами дифракции на прозрачном акустическом клине и на упругом клине.

Мы не упоминаем здесь о многих других научных и педагогических достижениях Василия Михайловича, отсылая читателя к статье в "Успехах математических наук", посвященной его 70-летию (57:3 (2002), 181-187; см. также: А.П. Киселев, В.П. Смышляев, "70 лет В. М. Бабичу", Зап. научн. сем., 275, ПОМИ, СПб., 2001, 9-16). Однако мы не можем не повторить теплые слова о замечательном человеке. Хорошо известны благожелательность и терпеливое отношение к сотрудникам, ученикам, знакомым - ко всем, кто имел и имеет счастье с ним общаться.

Мы желаем Василию Михайловичу отличного здоровья и дальнейших научных успехов. Желаем здоровья и успехов его детям и внукам, в том числе и внуку Василию Михайловичу Бабичу. 


\section{Список основных печатных работ В. М. Бабича}

[94] "О волновом поле вблизи точки падения предельного луча", Математические вопросы теории распространения волн, 29, Зап. научн. сем. ПОМИ, 264, ПОМИ, СПб., 2000, 22-32 (совм. с В. В. Камоцким); англ. пер.: "The wave field near the point of incidence of the limiting ray", J. Math. Sci. (N. Y.), 111:4 (2002), 3632-3638 (with V. V. Kamotski).

[95] "О принципе взаимности при рассеянии плоских электромагнитных волн на каноническом рассеивателе", Математические вопросы теории распространения волн, 30, Зап. научн. сем. ПОМИ, 275, ПОМИ, СПб., 2001, 17-24; англ. пер.: "On the reciprocity principle in the scattering of plane electromagnetic waves by a conic scatterer", J. Math. Sci. (N. Y.), 117:2 (2003), 3895-3899.

[96] О методе В.И. Смирнова - С.Л. Соболева явного решения задач математической теории дифракиии, Препринт № 1/2002, ПОМИ, СПб., 2002, http:// www.pdmi.ras.ru/preprint/2002/02-01.html (совм. с С. К. Кочегуевым).

[97] "О рассеянии высокочастотной электромагнитной волны вершиной идеально проводящего конуса. (Сингулярные направления)”, Зап. научн. сем. ПОМИ, 285 (2002), 5-14 (совм. с Д. Б. Дементьевым, Б. А. Самокишем, В. П. Смышляевым); англ. пер.: "Scattering of high-frequency electromagnetic waves by the vertex of a perfectly conducting cone (singular directions)", J. Math. Sci. (N. Y.), 122:5 (2004), 3453-3458 (with D. B. Dement'ev, B. A. Samokish, V. P. Smyshlyaev).

[98] "О распространении волн соскальзывания вдоль криволинейной поверхности анизотропного упругого тела", Математические вопросы теории распространения волн, 32, Зап. научн. сем. ПОМИ, 297, ПОМИ, СПб., 2003, 9-29; англ. пер.: "Propagation of creeping waves along the curvilinear surface of an anisotropic elastic body", J. Math. Sci. (N. Y.), 127:6 (2005), 2340-2352.

[99] Метод Зоммерфельда-Малюжиниа в задачах дифракиии, Изд-во СПбГУ, СПб., 2003, ISBN: 5-9651-0003-5, 92 с. (совм. с М. А. Лялиновым, В.Э. Грикуровым).

[100] "О ПЦ-анзаце", Математические вопросы теории распространения волн, 33, Зап. научн. сем. ПОМИ, 308, ПОМИ, СПб., 2004, 9-22; англ. пер.: "On PC ansatzs", J. Math. Sci. (N. Y.), 132:1 (2006), 2-10.

[101] "A new approach to the problem of the Rayleigh wave propagation along the boundary of a non-homogeneous elastic body", Wave Motion, 40:3 (2004), 209-223 (with N. Ya. Kirpichnikova).

[102] "Nongeometrical phenomena' in propagation of elastic surface waves", Surface waves in anisotropic and laminated bodies and defects detection, NATO Sci. Ser. II Math. Phys. Chem., 163, Kluwer Acad. Publ., Dordrecht, 2004, 119-129 (with A. P. Kiselev).

[103] "Об электромагнитных волнах соскальзывания при краевых условиях Леонтовича", Радиотехника и электроника, 50 (2005), 1-5; англ. пер.: "Creeping electromagnetic waves observed under the Leontovich boundary conditions", J. Commun. Technol. Electron., 50 (2005), 274-278.

[104] "О распространении поверхностных электромагнитных волн, аналогичных волнам Рэлея, в случае краевых условий Леонтовича", Математические вопросы теории распространения волн, 34, Зап. научн. сем. ПОМИ, 324, ПОМИ, СПб., 2005, 5-19 (совм. с А. В. Кузнецовым); англ. пер.: "Propagation of surface electromagnetic waves similar to Rayleigh waves in the case of Leontovich boundary conditions", J. Math. Sci. (N. Y.), 138:2 (2006), 5483-5490 (with A. V. Kuznetsov).

Первую часть списка см. в: УМН, 57:3 (2002), 183-187. Под номерами [115]-[118] указаны работы В. М. Бабича 1950-1960-х годов, не упомянутые в первой части списка. 
[105] "On Budaev and Bogy's approach to diffraction by the 2D traction-free elastic wedge", SIAM J. Appl. Math., 67:1 (2006), 235-259 (with V.V. Kamotski, L. Yu. Fradkin. B. A. Samokish, V. A. Borovikov).

[106] "О квазифотонах волн Релея (случай анизотропного упругого тела)", Математические вопросы теории распространения волн, 35, Зап. научн. сем. ПОМИ, 332, ПОМИ, СПб., 2006, 7-18 (совм. с А. В. Поскряковым); англ. пер.: "On quasiphotons of Rayleigh waves (the case of an anisotropic elastic body)", J. Math. Sci. (N. Y.), 142:6 (2007), 2521-2527 (with A. V. Poskryakov).

[107] "Квазифотоны и пространственно-временной лучевой метод", Математические вопросы теории распространения волн, 36, Зап. научн. сем. ПОМИ, 342, ПОМИ, СПб., 2007, 5-13; англ. пер.: "The space-time ray method and quasiphotons", J. Math. Sci. (N. Y.), 148:5 (2008), 633-638.

[108] "О вычислении значений функций Лежандра", Математические вопросы теории распространения волн, 36, Зап. научн. сем. ПОМИ, 342, ПОМИ, СПб., 2007, 14-30 (совм. с Д. Б. Дементьевым, Б. А. Самокишем); англ. пер.: "Computation of Legendre functions", J. Math. Sci. (N. Y.), 148:5 (2008), 639-649 (with D. B. Dement'ev, B. A. Samokish).

[109] "Прямое доказательство возможности факторизации матриц-функций”, Алгебра и анализ, 20:1 (2008), 3-33; англ. пер.: "Factorizability of matrix functions: A direct proof", St. Petersburg Math. J., 20:1 (2009), 1-22.

[110] "О рассеянии плоской волны прозрачным клином", Математические вопросы теории распространения волн, 37, Зап. научн. сем. ПОМИ, 354, ПОМИ, СПб., 2008, 5-18 (совм. с Н. В. Мокеевой); англ. пер.: "Scattering of the plane wave by a transparent wedge", J. Math. Sci. (N. Y.), 155:3 (2008), 335-342 (with N. V. Mokeeva).

[111] "Boundary layer approach to describe an interference head wave", Wave Motion, 46:3 (2009), 169-173.

[112] “С. Л. Соболев. Жизнь и творчество. Довоенный период", Неравенство Соболева. 70 лет спустл, Белая серия в математике и физике, 6, Изд-во "Тамара Рожковская", Новосибирск, 2009, 1-12.

[113] "Дифракция плоской волны на клине", Математические вопросы теории распространения волн, 38, Зап. научн. сем. ПОМИ, 369, ПОМИ, СПб., 2009, 5-15 (совм. с А. А. Мацковским).

[114] “Об одном классе топографических волноводов", Алгебра и анализ, 22:1 (2010), 98-107; англ. пер.: "A class of topographical waveguides", St. Petersburg Math. J., 22:1 (2011), 73-79.

[115] “Лучевой метод вычисления интенсивности волновых фронтов", Докл. АН СССР, 110:3 (1956), 355-357.

[116] “Лучевой метод вычисления интенсивности волновых фронтов", Вопросъ $\partial u$ намической теории распространения сейсмических волн, 5, 1961, 3-24 (совм. с А. С. Алексеевым, Б. Я. Гельчинским).

[117] “Лучевой метод вычисления интенсивности волновых фронтов в случае неоднородной анизотропной среды", Вопросы динамической теории распространения сейсмических волн, 5, 1961, 36-46.

[118] "О распространении волн Релея по поверхности неоднородного упругого тела произвольной формы", ЖУурн. вычисл. матем. и матем. физ., 2:4 (1962), 652-665 (совм. с Н. Я. Русаковой); англ. пер.: "The propagation of Rayleigh waves over the surface of a non-homogeneous elastic body with an arbitrary form", Comput. Math. Math. Phys., 2 (1962), 719-735 (with N. J. Rusakova). 